\title{
Bellagio consensus: Recommendations for action to increase access to highly effective, long-acting, reversible contraception
}

Population Council

Follow this and additional works at: https://knowledgecommons.popcouncil.org/departments_sbsr-rh

Part of the International Public Health Commons, Maternal and Child Health Commons, Obstetrics and Gynecology Commons, Social and Behavioral Sciences Commons, and the Women's Health Commons How does access to this work benefit you? Let us know!

\section{Recommended Citation}

"Bellagio consensus: Recommendations for action to increase access to highly effective, long-acting, reversible contraception." New York: Population Council, 2012. 


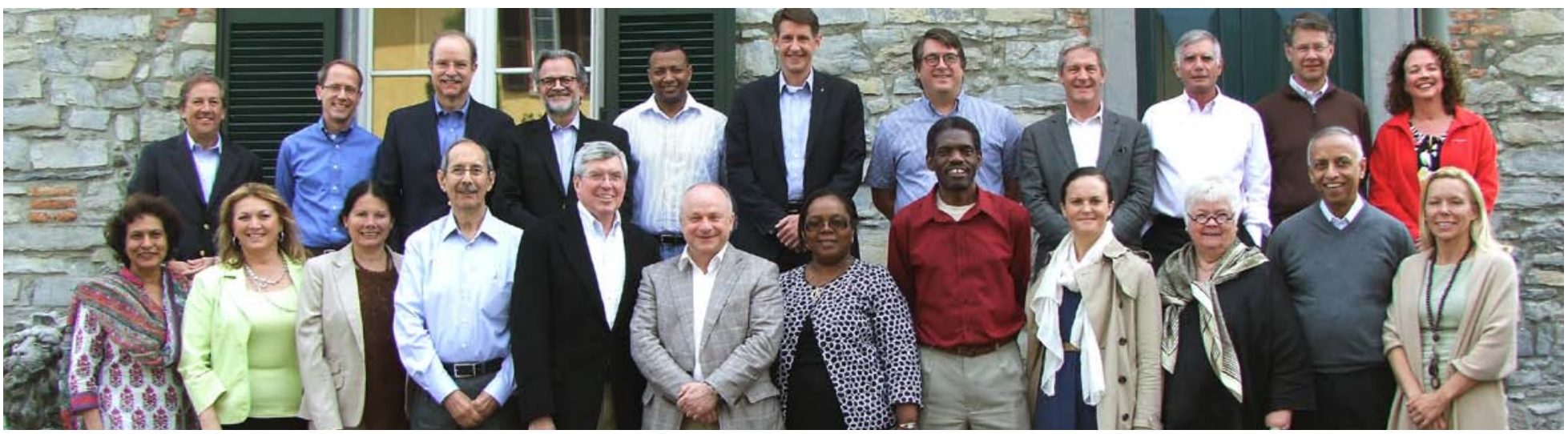

International experts meet to discuss ways to increase access to highly effective, long-acting, reversible contraception (LARCs). The meeting was hosted by the Population Council, the International Federation of Gynecology and Obstetrics, and the Reproductive Health Supplies Coalition.

\section{More than 200 million women in the developing world want to prevent pregnancy but are not using modern contraception.}

For many of these women, particularly the poor, significant structural barriers obstruct their access to the full range of contraceptive methods. Women's desire to delay, space, or limit pregnancies is often resisted by their families or communities. Public-sector family planning programs, which are the main source of contraception in most developing countries, typically offer limited options, and supplies are not always in stock. Health care providers may not be trained to provide the counseling and services that women need to achieve their reproductive goals. These factors leave poor women facing a substantial risk of unintended pregnancy, unsafe abortion, and maternal and infant mortality and morbidity.

Highly effective, long-acting, reversible contraceptives (LARCs) such as the intrauterine contraceptive device (IUD) and contraceptive implants often are out of reach for women in developing countries.

Because of the need for a skilled provider and the low priority given to making these methods a viable option for women, family planning programs often fail to offer women a full range of methods, including those that are most effective and appropriate for women who want to postpone their first pregnancy, delay their next pregnancy, or limit future births.

Globally, more than 40 percent of pregnancies are unintended. Two-thirds of these pregnancies could be prevented if women with an unmet need for contraception had access to their choice of safe and effective methods. Having access to a variety of contraceptive options and services based on informed choice allows women to choose the method best suited to their needs. Because highly effective, long-acting, 
reversible contraceptives maintain their effectiveness for a long period, temporary supply chain disruptions have little impact on users' lives. Likewise, LARCs typically cost less per month of use than less-effective reversible contraceptives. For example, because of their more prolonged use and higher effectiveness, copper IUDs cost substantially less per month of use to prevent an unintended pregnancy than other reversible methods. Further, development of new implants and improved pricing options for existing implants and intrauterine contraceptive systems (IUSs) would make the cost of their use comparable to that of other contraceptive products in many national markets.

Since 1984, international agreements have reaffirmed the right of women to decide on the number and timing of their children as well as the means to achieve these intentions. If access to LARCs such as intrauterine contraception (IUSs or IUDs), implants, and, in the future, longer-acting contraceptive vaginal rings and injectables were increased, unintended pregnancies could be significantly reduced and women's health significantly improved. LARCs are more effective than other contraceptive methods in reducing the probability of unintended pregnancy. Consequently, greater use of LARCs would reduce the number of unintended pregnancies and unsafe abortions, and improve maternal and infant health. In addition to these health benefits, meeting women's contraceptive needs would help increase their economic opportunities and their contributions to their families' well-being as well as to national economic growth through greater income per capita.

The need for LARCs will continue to grow. Because of the young age structure of populations in developing countries, the number of potential users of contraception will increase from 144 million in 2005 to about 214 million by 2020. Of these, we estimate that approximately 57 million women will be seeking LARCs by 2020. Research on policies and programs has demonstrated that the use of LARCs increases when women are provided with greater method choice and a concern for equity shapes the design of health care delivery strategies. The success of these programs provides evidence for the continued expansion of such efforts.

\section{BELLAGIO MEETING}

In May 2012, the Population Council, the International Federation of Gynecology and Obstetrics (FIGO), and the Reproductive Health Supplies Coalition (RHSC) hosted a meeting at the Rockefeller Foundation's Bellagio Center to discuss opportunities to increase access to LARCs to accelerate progress toward meeting the Millennium Development Goal of universal access to reproductive health services. Participants, including service providers, donor representatives, policymakers, procurement specialists, manufacturers, and public health officials, reached consensus on the following analysis and recommendations.
We believe that women are qualified to make informed choices about the contraceptive that best meets their needs, if access is provided, correct information is available, and quality of care is ensured. 
Access to all contraceptives, including LARCs, must be based upon the right of women and men to the full range of reproductive health services. The compelling public health and economic benefits of expanding women's access to LARCs require new policies and perspectives. The group called for the implementation of the following actions to ensure such increased access.

\section{RECOMIMENDATIONS}

Change policies: $\quad$ Policymakers should increase the priority given to efforts to reduce unintended pregnancies by meeting the unmet need for highly effective, long-acting, reversible contraceptive methods as part of a comprehensive range of method options. This priority should be reflected in financing, procurement, and human resource policies as well in the registration, introduction, and distribution of contraceptive methods.

Reduce cost: $\quad$ For many women in developing countries, LARCs are unavailable or are attainable at a cost much greater than women are able to pay. For these women, access to LARCs is dependent on programs largely financed by donors and national governments. Despite the relatively high initial cost of LARCs, developing-country governments, working with donors and NGOs, have expanded the level of LARC use over the past five years. To sustain this progress, manufacturers, international donors, and national procurement systems should collaborate to develop strategies to increase the affordability of procuring and supplying LARCs. They should also work to maintain a reliable supply of LARCs within countries to allow use of these methods as desired by women. Greater availability and use of LARCs will help increase affordability.

Integrate LARCs into health systems:

To ensure that women have a range of choices across product classes, public and private health care delivery systems should integrate LARCs into their training, counseling, service provision, logistics, and information management. Because many providers of postabortion and postpartum care have the counseling and clinical skills needed for initiation of LARCs, more attention should be focused on postabortion and postpartum provision of LARCs as one of the simplest ways to increase access to those in greatest need.

\section{Ensure} availability and access:

Train and supervise qualified providers:

Engage support of professional associations:

Gather and use data to ensure product quality and improved care:

\section{Organizations engaged in promoting reliable access to contraceptive methods should ensure} that long-acting, reversible contraceptive methods are available in public and private markets, and that products and services are accessible to women in the poorest segments of each country. Governments and donors should promote informed choice by supporting a variety of contraceptive choices rather than particular methods.

National family planning, reproductive health, and women's health program managers should develop competency-based training and on-the-job supervisory systems to ensure that qualified staff, both medical and paramedical, are in a position to provide counseling, insertion, and removal of LARCs on demand.

Professional associations, including FIGO, the International Confederation of Midwives, the International Council of Nurses, and similar national and regional societies should work with national governments and private-sector organizations to train medical and nonmedical providers and otherwise facilitate women's access to information and services.

Data on the use, quality of care, and effectiveness of LARCs and other family planning methods in resource-limited settings should be developed or, where already available, disseminated. These data should be reviewed by WHO and by professional associations such as FIGO to determine whether additional guidance is needed on the public health benefits of expanding use of LARCs. Indicators should be developed and deployed that measure the extent to which women have easy access to a range of high-quality contraceptive methods, including LARCs.

\section{Develop a} strategic plan to accomplish these goals:
Representatives of national governments, donors, contraceptive manufacturers, program managers, NGO leaders, and representative users should meet before the end of 2012 to develop a detailed strategic plan, based on a joint diagnosis of the most consequential barriers to greater access and affordability of highly effective, long-acting, reversible methods. The strategic plan is a tool for increasing choices for women, ensuring reliable supplies, enhancing service quality, and improving reproductive health. 
The provision of LARCs and other contraceptives and reproductive health care must be based on informed choice, voluntarism, and equity. These ethical principles are critical to ensure that women's needs are at the center of any discussion of technologies, and are consistent with plans of action adopted by the International Conference on Population and Development (ICPD) in 1994, the Conference on Women in 1995, WHO's Global Strategy on Reproductive Health in 2004, and the UN Global Strategy for Women's and Children's Health in 2010.

We ask that these actions be fully implemented by 2020, with significant progress made by 2015 consistent with the achievement of the Millennium Development Goals. These actions will improve the health of women, expand their opportunities, and improve the welfare of their families and communities. Moreover, countries will see the economic dividends of lower fertility and over time a changing age structure with less dependency and greater work force participation. We ask that these recommendations form part of the analysis and discussion at the Family Planning Summit on July 11, 2012, in London. We ask also that the plans of action emerging from this summit include specific recommendations for guaranteeing informed choice and equity, including increased access to highly effective, long-acting, reversible contraception as part of a broader multi-method strategy for improving women's health and options.

MEETING PARTICIPANTS:

(Bottom row, left to right): Shahida Zaidi, Former FIGO Vice President; Turkiz Gokgol, The Susan Thompson Buffett Foundation; Laura Miranda, IPPF/WHR; Anibal Faúndes, FIGO; Peter Donaldson, Population Council; Klaus Brill, Bayer Pharma AG; Gloria Asare, Ghana Health Service, Ghana;

Roland Edgar Mhlanga, Ministry of Health, South Africa; Julia Lowe, Bill \& Melinda Gates Foundation; Jill Sheffield, Women Deliver; Sabaratnam Arulkumaran, FIGO; Saundra Pelletier, WomanCare Global. (Top row, left to right): Alan Staple, The Clinton Foundation Health Access Initiative; Jared Stamm, Population Council; John Skibiak, Reproductive Health Supplies Coalition; John Townsend, Population Council; Aron Betru, United Nations Foundation; Koen Kruytbosch, Merck/MSD; Scott Radloff, USAID; Ian Askew, Population Council; James Trussell, Princeton University; Karl Hofmann, PSI ; Victoria Hale, Medicines360. (Not pictured: Eric Dupont, UNFPA)

The Population Council confronts critical health and development issues-from stopping the spread of HIV to improving reproductive health and ensuring that young people lead full and productive lives. Through biomedical, social science, and public health research in 50 countries, we work with our partners to deliver solutions that lead to more effective policies, programs, and technologies that improve lives around the world. Established in 1952 and headquartered in New York, the Council is a nongovernmental, nonprofit organization governed by an international board of trustees.

(c) 2012 The Population Council, Inc. $\quad$ www.popcouncil.org 